\section{Edward Charles Pickering}

By Marcus Benjamin, Ph.D. $\prod_{\text {vancement of Science will meet in Cleveland, Ohio, }}^{\text {His year the American Association for the Ad- }}$ to which place it returns after an absence of twentyfour years. The presiding officer of the meeting will be Edward Charles Pickering, the most eminent of living astronomers in the United States.

Prof. Pickering was born in Boston, Mass., on July 19th, 1846. He is the son of Edward P. and Charlotte Hammond Pickering. His ancestry on his father's side goes back to John Pickering, who came from England and settled in Salem in 1642, and includes among other distinguished persons famous in the history of our country, Col. Timothy Pickering, who after service under Washington in the field became Postmaster General, then Secretary of War, and finally Secretary of State during the administrations of Washington and Adams.

Young Pickering was educated at the famous Boston Latin School, and then passed to the'Lawrence Scientific School of Harvard, where he was graduated in 1865 with the degree of B.S., having taken the course in civil engineering.

His ability had been so evident during his undergraduate years that he was at once made an instructor in mathematics in the Lawrence School, but his stay was short; for in 1868 he was called to fill the Thayer chair of physics in the then recently organized Massachusetts Institute of Technology, where he remained for nine years. During this period he organized the first working laboratory in physics in the United States and the methods inaugurated by him have since been adopted elsewhere. In connection with his work he prepared the volume on "Physical Manipulation" (1874), a text-book that has received high commendation and is still universally esteemed.

In 1876, soon after the death of Prof. Joseph Winlock, he was called to the chair of Geodesy and Astronomy in Harvard with the directorship of the great observatory there, which place he has since held.

With his extraordinary zeal for investigation and at his disposal a splendid instrument of 24-inch aperture, the lens of which was ground by Clark, Prof. Pickering at once began those special studies that have gained for him and the Harvard Observatory so much renown. These studies have been largely devoted to examination of the light and spectra of the stars for the purpose of determining their brightness. For this object he devised a mechanical meridian photomete object he devised a mechanical meridian photometer
with which he has made over a million and a half measurements of the light of the stars. The details of this work were given in a catalogue entitled "Harvard Photometry," in which he gives the magnitude of over 4,000 stars, and in a later publication simila measurements of more than 21,000 stars are given. $\mathrm{He}$ measured Jupiter's satellites while they were undergoing eclipse from 1878 to 1891 , as well as the satellites of Mars and other faint objects. Subsequent to the death of Henry Draper he began the application of photography to astronomy and in a memorial to his friend he undertook an investigation of the spectra of the stars by photography on a scale greater than ever before attempted, resulting in the publication of an elaborate memoir dedicated to the memory of his an elabo

In consequence of a fund of $\$ 250,000$ left by Uriah A. Boyden to the observatory for the special purpose of studying the stars at high altitudes, he established, in 1890, an observing station at Arequipa, Peru, and there his brother, William H. Pickering, observed the stars of the southern heavens, thus extending the work that had been begun in Cambridge, until photographic charts of the entire heavens from pole to pole have been made. These and other studies of the work accomplished under his direction have for the most part been published in the "Annals" of the Harvard Observatory of which nearly one hundred quarto volumes have been given to the world and of these more given to the world, and half have been issued under than one half have been issued under His other scientific activities, and they have been many, included services as a member of the U. S. Nautical Almanac Expedition sent to Mount Pleasant, Iowa, to observe the total eclipse of the sun on August 7th, 1869, and he was also a member of the party sent by the U. S. Coast Survey for a similar purpose to Xeres, Spain, in December, 1870. The subjects of mountain surveying, the height and velocity of clouds have attracted his attention, and he did much toward the organization of the Appalachian Mountain Club of which he was the first president in 1877 , and again served that club in a like capacity in 1882.

His many services to science have not passed without recognition. He received the Henry Draper gold medal from the National Academy of Sciences in 1877. The Royal Astronomical Societ of London gave him a gold medal in 1886 for his photographic researches, and again in 1901 for his studies on variable stars. He received the Rumford medals in 1891 and the Bruce medal from the Astronomical Society of the Pacific in 1908. His own Harvard in 1903, California in 1886, Michigan in 1887, Chicago in 1901, and Pennsylvania in 1906, have conferred the degree of LL.D. upon him, while Victoria gave him a Sc.D. in 1900 and Heidelberg in 1903 bestowed upon him the degree of Ph.D. The German Emperor conferred upon him in 1911 the order Pour le Merite with the rank of knight, thus indicating the high apprecia-

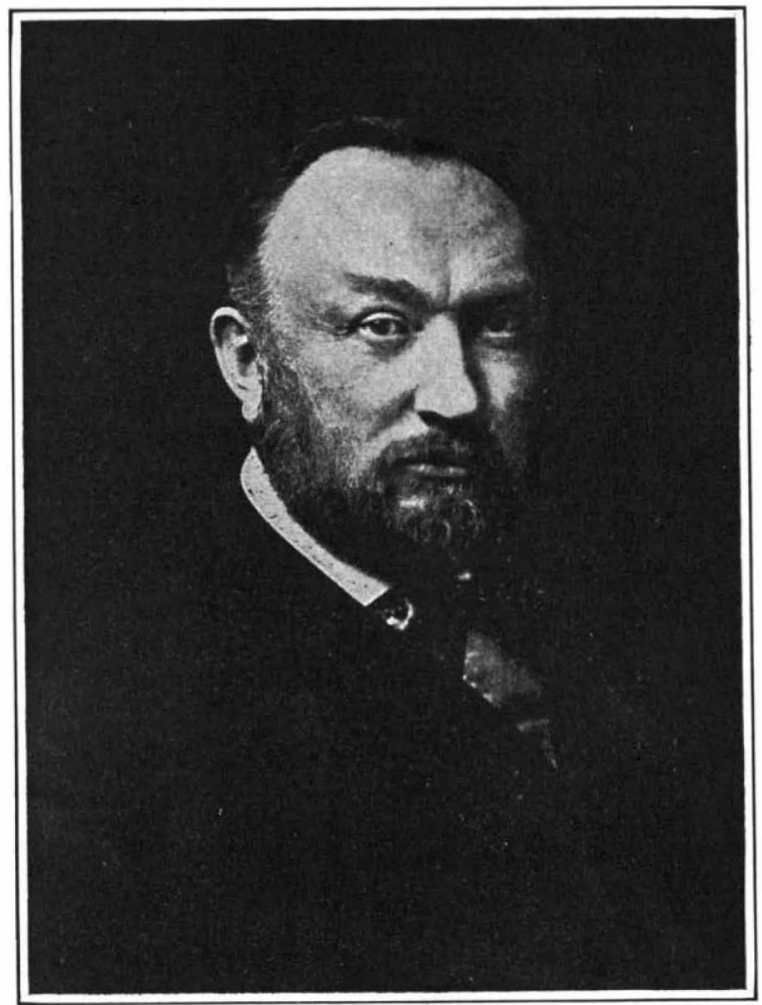

Prof. Edward Charles Pickering. President of the American Assoclation for the Advancement
of Sclence.

tion with which his work is regarded by the savants of Germany.

His elections to scientific academies have been numerous. In 1873 he was chosen to membership in the National Academy of Sciences, and he has long been a fellow of the American Academy of Arts and Sciences (vice-president in 1877) and a member of the American Philosophical Society since 1896 (vicepresident in 1909). He also holds honorary or corresponding connections with the Royal Society of London, the Royal Astronomical Society and of the great academies of sciences in St. Petersburg, Berlin, and Rome, as well as of many other less well known.

He was elected to the American Association for the Advancement of Science at its Salem meeting in 1869 and was advanced to the grade of fellow in 1875 . His affliations have always been with the sections devoted to mathematics and astronomy, and physics. He was chosen to preside over the section on the physical sciences in 1877, and at that meeting presented an address on the Endowmenit of Research. No astronomer has been called to fill the high office of president of the American Association since 1893, when the late William Harkness held that important office. At the meeting held in Washington a year ago, when the claims of astronomers were considered, the candidate

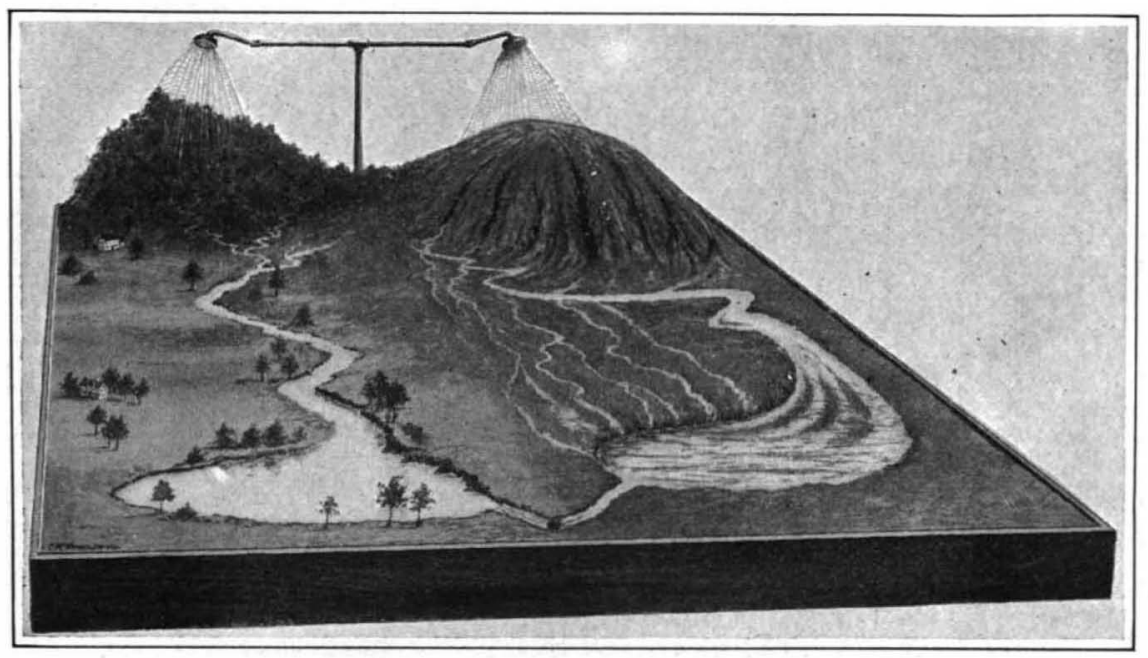

Working model for demonstrating to pupils in public schools, the processes of erosion on deforested slopes. who at once commanded the recognition of his col(eagues by his distinction in his chosen science, was Prof. Pickering, who was then unanimously chosen to preside at the Cleveland meeting, which will be held during the present week.

\section{A Demonstration of Forestry Erosion Processes By Stephen Byrd}

XPERTS of the Government have been successful $\mathrm{C}_{\text {in }}$ the construction of a striking working model showing the processes of erosion on deforested slopes. It is for the use of pupils in public schools who are taking courses in nature study, elementary agriculture and physical geography.

The model, about seven feet square, consists of two hills sloping down into two valleys through which two streams wind in and out through farm land and lead into two lakes at the front of the landscape. Both hills are made of the same kind of soil, but one is covered thickly with twigs, young trees, or shrubs, to simulate a forest, underneath which is a heavy carpet of moss representing the layer of leaves and twigs which covers the ground in the real forest, while the other hill is bare of all vegetation.

By means of a suitable sprinkling device on the ends of a "T" about $11 / 2$ feet above the crests of the hills water in the form of rain is made to fall with equal force upon the two hills. On the forested slope its fall is broken by the foliage and it drops gently upon the moss-covered surface of the ground. . The moss and the soil beneath, which is kept soft and porous by the protective cover, quickly absorb the "rain" and allow it to seep out as clear water farther down the slope, thus forming a mountain stream which flows through a green and fertile valley into a clear lake at the lower end of the model.

On the other slope the "rain" beating down upon the unprotected and hardened surface washes deep gullies in the hillside, carries the soil into the turbid stream which drains the valley below, and thence into a muddy lake. The erosion on the slope loosens stones, which are carried down upon the valley farms; the silt deposited in the channel of the stream diverts the water, which opens up gullies through the dry land the main stream is made shallower and wider and often overfiowers into the fields; island and silt bars rise in the stream; and deltas are built up in charac teristic form at the entrance to the lake.

The erosion processes which work themselves out in the model, the wearing down of the hill, the silting up of the stream bed, the gradual shifting of the course of the stream, the formation of deltas and sand bars in the lake, and the gradual opening up of watercourses through them are all typical of the processes constantly going on in nature and show strikingly the close relationship between forests and surface formation. It is the same process of erosion on a larger scale which, after the destruction of our forests, causes the removal of the top soil from our slopes, cuts them up into gullies, and deposits sand and gravel upon the fertile alluvial soil of the bottom lands, in storage reservoirs, or in the channels of streams, where it impedes navigation and causes overflow.

While the model is not intended primarily to show more than the erosion processes, it can be used to show also that a forest-covered slope acts as a reservoir in impounding the water and allowing it to seep slowly into the streams, and, on the other hand, that water runs off the surface of a bare slope as soon as it falls, resulting in floods when the precipitation is heavy and in droughts during a dry season. If the sprinkler is stopped and all the water taken out of both of the stream and the lakes, the lake on the forest side will, within a few hours, receive a considerable amount of water as seepage from the wooded hillside, while the other lake will remain practically empty. When the water is first turned on, that which comes from the forested hill will be slightly muddy, but will clear after running for a few minutes, and the mud will soon settle. Erosion will set in upon the deforested hill and the land below in a few hours.

In some of the models white sand and pebbles and small goldfish or turtles in the clear lake, have added a touch of realism and brought out the clearness of the water. Other ideas to add to the picturesqueness and instructiveness of the model have also been evolved, such as a road running through the fields, bridges across the streams, and a little farm house or barn appropriately placed. The bridge across the muddy stream is represented as damaged by floods, and the road on that side of the model muddy and deeply furrowed. In the construction of 
Rumoly Bullotin No. 4

\section{Plowing is Man's Heaviest Labor}

$1 / 8$

OF U.S. PLOWED ANNUALLY

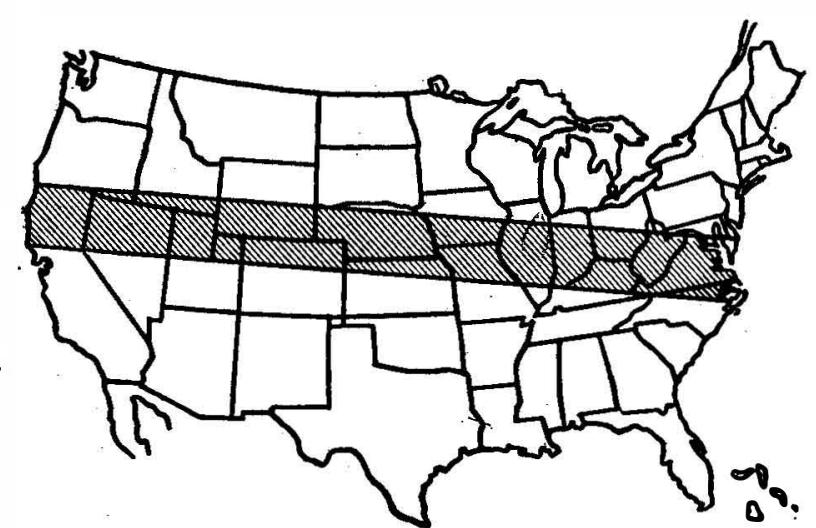

Our biggest and hardest job in the United States is Plowing. Las year we plowed $275,000,000$ acres, at a cost of $\$ 450,000,000$.

This means turning over a weight of 2,000,000,000 tons of earth.

Every 5 square miles of plowing /means a distance traveled of 25,000 miles. It means a single furrow around the whole earth. Every loaf of bread requires the plowing of a furrow 48 feet long. To plow one acre is a whole day's work for one main and one horse; bat it is only $\mathbf{3 0}$ minutes' work for one man and a Tractor. In a test at Purdue University, 3 Rumely Tractors, hanling 50 plows, plowed an acre in $41 / 4$ minutes.

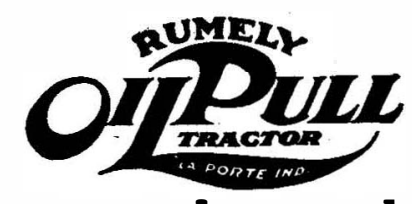

These Tractors plow, not by horse-muscle, but by BRAINS and KEROSENE. Rumely Products Co.

Power-Farming Machinery La Porte, Ind.

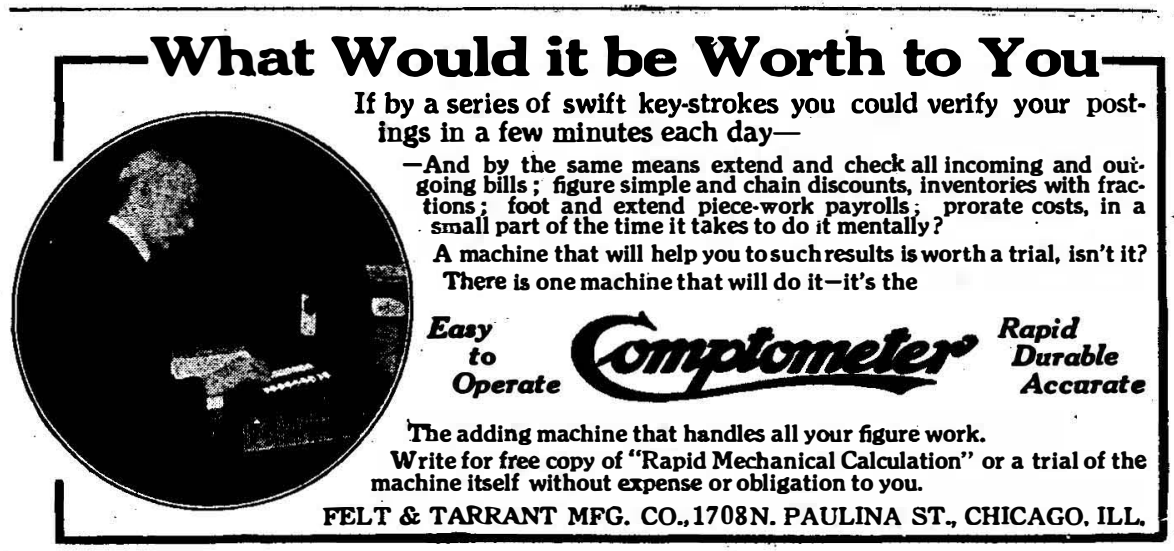

Models a d Experimental Work Patented Articles and Metal Specialties INVENTIONS DEVELOPED

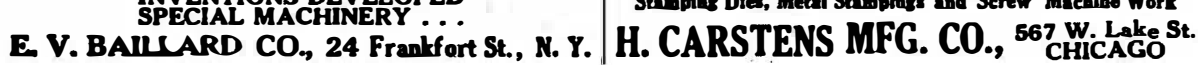

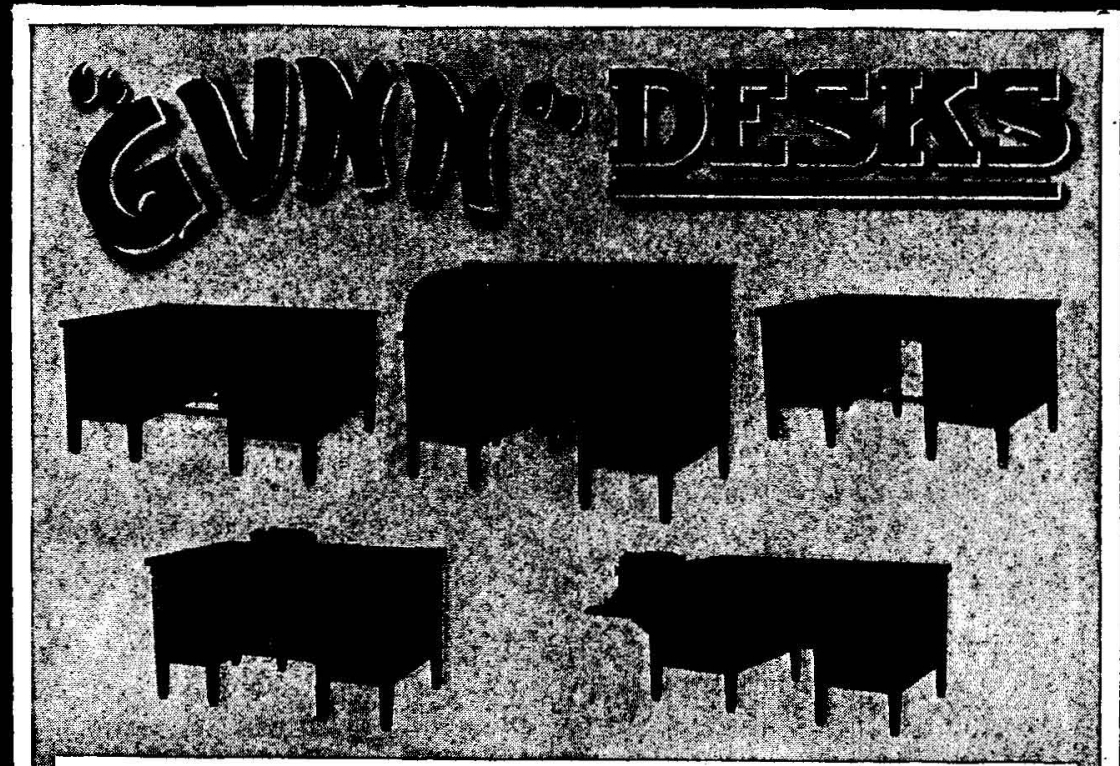

THE GUNN FURNITURE COMPANY, Grand Rapid, Michigan OFFICE DESKS, SECTIONAL BOOKCASES, FHING DEVICES perates in a similar manner; both can easily be carried to a patient's bedside.

Forestry Erosion Processes (Concluded from page 555.)

the model a tray from 4 to 7 feet square and 6 inches deep, having been at first waterproofed, is filled with 4 inches of rubble and earth, with the general slant of the surface toward the center of the front of the tray. Slight depressions are made as foundations for the two streams
and for the two lakes. Over this is next placed 1 to 2 inches of mortar, consisting of one part cement and two parts sand. The stream beds and lake depressions are worked in before the mortar sets, taking care that the outlets of the lakes are only slightly lower than the intakes at the mouths of the streams. This cement, when dry, is waterproofed with hot paraffin, and a gutter is run along the front to receive the drippings of water as well as the runoff from the lakes. This water should empty into a waste pipe. In the rear of the model two mounds of earth, about $1 \frac{1 / 2}{2}$ feet high, should be placed, with a depression between them. One of the mounds is covered thickly with moss, and through this small twigs or trimmings of hedges should be stuck to represent a forest. Stretches of nearly level land should extend from the bases of the hills to the lakes. The land below the forested hill should be covered with stream and lake covered with moss to prevent washing. The other section should be barren and strewn with stones and small boulders.

New Information on Forest Fires

THE subject of Forest Service Bulle1 tin 117 has been strikingly brought to the public mind during the last few years by reason of the exceptional number of
extensive forest fires, which have arisen both on private and on public lands. The fact that the fall of 1910 was one of exceptional drought in the western United States accounts for the prevalence of these fires. but they occur to a greater or less extent every year, and are a source of inestimable loss to the people of this country. The present is an opportune time for the discussion of this subject, partly because of the extent of this enormous loss, but more because public attention may now be easily attracted, inasmuch as the general reader has recently been able to see and to figure out for himself the causes and the damage occasione by these fires.

Mr. Fred G. Plummer, the geographei of the Forest Service and author of this bulletin, has considered the subject, under the following headings: Sources and dires: Causes of Fires; Smoke Phenomena of Forest Fires; Historic Fires; Statistic of Damage and Loss.

The report is based upon statistics re ceived from every State and Territory in the Union and as far back as there are available records. Every bit of information was reduced to a common standar and a card system devised for use in future compilation of forest fire stati tics. The figures given in the final table of forest fires in the United States, Canada and Newfoundland embrace a record of the causes and of the number of fires, total area burned, and the amount and value of timber consumed. Credit is given by the author to others who had previously gathered statistics on the subject, but Mr. Plummer has succeeded in bringing together the most complete record which is presented in the most compact and intelligent manner. The reader will be impressed with the great care and technical skill exhibited in the preparation of this new and real unique report. While the bulletin is necessarily technical in some parts, as for instance in the discussion which deals with smoke phenomena of forest fires, yet the non-technical reader will find a mass of data that will enable him to see for himself the great problem confronting the America people.
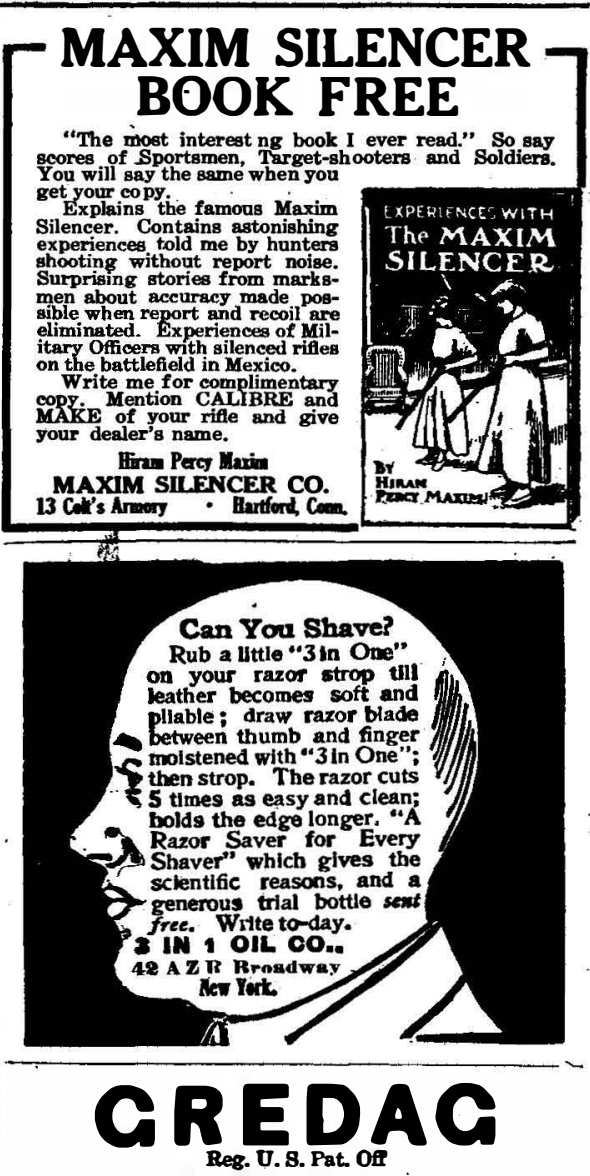

It is the only grease that contains Acheson Graphite the only graphite that is Pure and Gritless. It possesses the combined merits of
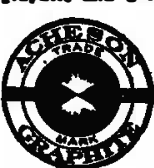

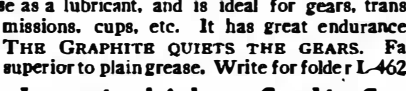
Interaational Acheson Graphite
Niagara Falls, N. Y.

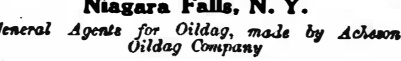

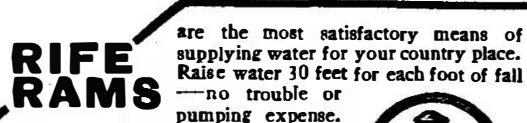

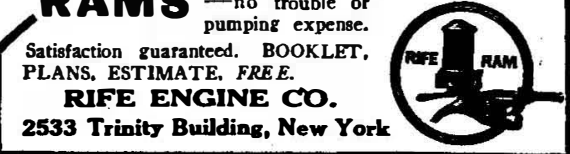
SELENIUM AND ITS REMARKABLE PROPERTIES are fully described in Scientifi American Supplement 1430. The paper is illustrated by Munn \& Co., Inc., and all newsdealers.

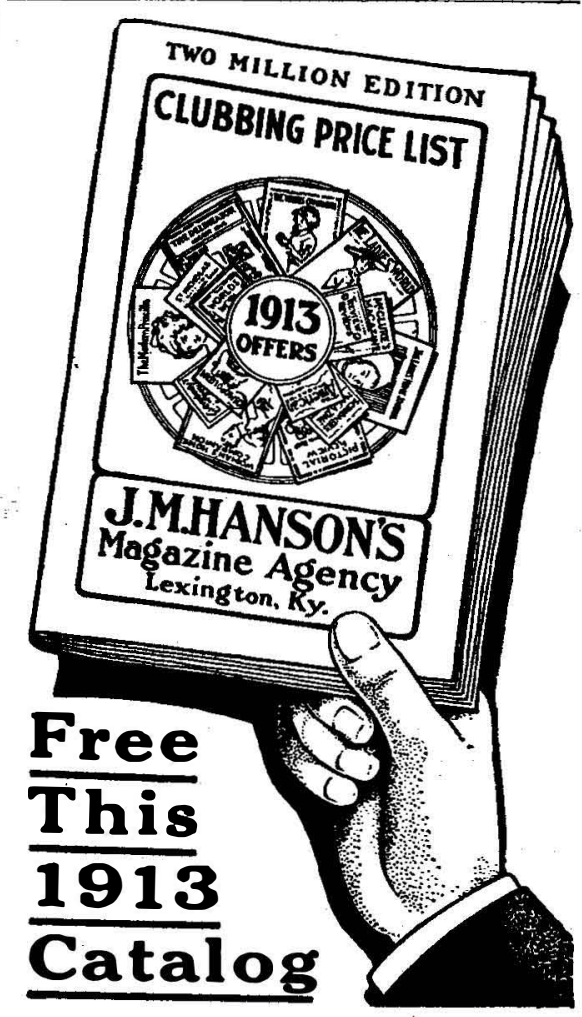

WRITE FOR IT

J. M. HANSON'S Magazine Agency

the largest in the world, furnishes all Low Prices and quick, accurate, and

Save Magazine Money

Our 1913 Catulog (44 pages) lists more
than 3000 Periodicals and Club Offere It's a BIG MONEY SAVER, and is FRE: Send Us Your
Name and Address NOW

5. M. HANSONS MAGAZINE AGENCY 228 Henos Block, Laimpon, $K$. 